\title{
Apoptosis induced by pneumolysin in human endothelial cells involves mitogen-activated protein kinase phosphorylation
}

\author{
AIE ZHOU ${ }^{1 *}$, HONG WANG $^{1 *}$, KAI LAN $^{2}$, XUEMEI ZHANG ${ }^{1}$, WENCHUN XU ${ }^{1}$, \\ YIBING YIN $^{1}$, DAIRONG LI ${ }^{3}$, JUN YUAN ${ }^{1}$ and YUJUAN HE ${ }^{1}$ \\ ${ }^{1}$ Key Laboratory of Laboratory Medical Diagnostics, Ministry of Education, Faculty of Laboratory Medicine, Chongqing \\ Medical University, Chongqing 400016; ${ }^{2}$ Laboratory Department, Guangdong Provincal Hospital of TCM, \\ Guangzhou 510120; ${ }^{3}$ Department of Pneumology, The First Affiliated Hospital of \\ Chongqing Medical University, Chongqing 400016, P.R. China
}

Received November 10, 2011; Accepted December 19, 2011

DOI: $10.3892 / \mathrm{ijmm} .2012 .946$

\begin{abstract}
Pneumolysin (Ply) is an essential virulence factor of $S$. pneumoniae, which can induce apoptosis in a variety of host cells to facilitate infection of pathogenic bacteria by as yet unclear mechanisms. To confirm the apoptosis-inducing properties of pneumolysin in endothelial cells, human umbilical vein endothelial cells (HUVECs) were exposed to pneumolysin. The proliferation of HUVECs was inhibited by pneumolysin in a dose- and time-dependent manner. Flow cytometry analysis and ultrastructural changes of the cells indicated the apoptotic response. Exposure to pneumolysin significantly increased the number of apoptotic cells and the activities of caspases-3 and -8. This change was associated with activation of p38 mitogen-activated protein kinase (MAPK) and suppression of extracellular signaling regulation kinase (ERK) $1 / 2$. Pre-exposure to the $\mathrm{p} 38$ MAPK inhibitor SB-203850 prevented human endothelial cells from apoptosis induced by pneumolysin. In conclusion, these findings demonstrate that pneumolysin induces apoptosis in endothelial cells and the involvement of p38 MAPK activation and ERK1/2 deactivation.
\end{abstract}

\section{Introduction}

S. pneumoniae is one of the most common opportunistic pathogens, which is commonly colonized on the nasopharynx asymptomatically and translocation to lungs, brain and blood leads to pneumonia, otitis media, pneumococcal meningitis and sepsis (1).

Correspondence to: Dr Yujuan He or Dr Jun Yuan, Faculty of Laboratory Medicine, Chongqing Medical University, 1 Yixueyuan Road, Yuzhong District, Chongqing 400016, P.R. China

E-mail: yjhemail@126.com

E-mail: yj6848@yahoo.com.cn

*Contributed equally

Key words: pneumolysin, human umbilical vein endothelial cells, apoptosis, caspase, p38 mitogen-activated protein kinase, extracellular signaling regulation kinase $1 / 2$
Pneumolysin (Ply) is an essential virulence factor in S. pneumoniae (2). Ply has four domains and is composed of 471 amino acid residues, with a molecular weight of $53 \mathrm{kDa}$ $(3,4)$. It belongs to the family of thiol-activated, cholesterolbinding toxins which exert direct cytotoxic effects on host cells by forming ring-shaped transmembrane pores.

Vascular endothelial cells play an important role against bacteria and their virulence factor entry into the blood. It's well known that apoptosis regulation is modulated by multiple phosphorylations of several different protein kinases, including the major subtypes of the mitogen-activated protein kinase (MAPK) family: extracellular signaling regulation kinase (ERK), ERK5, c-Jun N-terminal kinase (JNK) and p38 MAPK (5). It has been shown that ERK is associated with cell survival, whereas p38 MAPK and JNK are involved in apoptosis. However, the involvement of the aforementioned pathway in pneumolysin-induced apoptosis in vascular endothelial cells remains unclear.

Caspases are essential components of the apoptotic response (6). They belong to a group of enzymes known as cysteine proteases and possess the ability to cleave after an aspartate (AsP) residue in their substrate (7). N'Guessan et al (8) has confirmed that Ply-induced apoptosis in macrophages is dependent on caspases during pneumococcal infections. In contrast, Ply-induced apoptosis was not involved in the activation of the caspase pathway in dendritic cells (9). In this regard, it is still necessary to clarify whether caspases contribute to pneumolysin-induced apoptosis in vascular endothelial cells.

Exposure of neutrophils to viable pneumococci caused apoptosis and necrosis of the cells, which has been shown to be associated with pneumolysin. The role of pneumolysin in apoptosis is also supported by its ability to induce apoptosis of neuronal cells, dendritic cells, macrophages and cochlear cells (8-11). By comparing S. pneumoniae and its isogenic Ply deletion mutant, pneumolysin has been found to be implicated in HUVEC and type-II alveolar epithelial cell apoptosis $(8,12)$.

Therefore, the primary objective of the present investigation was to clarify whether human endothelial cells undergo apoptosis following purified Ply protein exposure and, if so, establish the involvement of the MAPK family and caspase pathways. 


\section{Materials and methods}

Cell culture. Human umbilical vein endothelial cells (HUVEC) were purchased from the American Type Culture Collection. Cells were cultured in DMEM medium containing $10 \%(\mathrm{v} / \mathrm{v})$ fetal calf serum, penicillin $(100 \mathrm{IU} / \mathrm{ml})$ and streptomycin $(100 \mathrm{~g} / \mathrm{ml})$ at $37^{\circ} \mathrm{C}$ in a humidified atmosphere of $5 \% \mathrm{CO}_{2}$ and the growth medium was changed every other day until cells reached $80 \%$ confluence. The deletion of Alanine at the 146 amino acid site of Ply ( $\triangle$ A 146 Ply or Ply mutant) was produced as previously described (13). This mutant has nearly lost its pore-forming activity. Ply was produced as described elsewhere (14).

MTT assay. HUVEC cells were grown to the mid-logarithmic phase and diluted to obtain a $2.5 \times 10^{4} / \mathrm{ml}$ solution. Cells were then exposed to Ply of various concentrations $(0.1,0.5,1,5$, $10 \mu \mathrm{g} / \mathrm{ml})$ for the indicated times $(0,24,48,72$ and $96 \mathrm{~h})$. Briefly, 200- $\mu 1$ aliquots of cell suspensions were plated on a 96-well plate, and then Ply at the concentrations of $0.1,0.5,1$, $5,10 \mu \mathrm{g} / \mathrm{ml}$ was added into the wells and incubated for 24,48 , $72,96 \mathrm{~h}$, followed by the addition of $20 \mu \mathrm{l}$ of MTT solution $(5 \mathrm{mg} / \mathrm{ml})$. The plate was incubated at $37^{\circ} \mathrm{C}$ for $4 \mathrm{~h}$, and the supernatant was removed. The culture medium served as the negative control. The absorbance of the wells, including the blanks, was measured at the wavelength of $492 \mathrm{~nm}$ after the addition $150 \mu 1$ of DMSO to all wells. The experiment was repeated five times. The $\mathrm{IC}_{50}$ values were calculated and the cell proliferation inhibitory rate was determined by the equitation: $\operatorname{RI}(\%)=\left[1-\mathrm{A}(492)_{\text {treated }} / \mathrm{A}(492)_{\text {control }}\right] \times 100 \%$.

Morphological examination. HUVEC cells were grown to the mid-logarithmic phase and diluted to gain a $2 \times 10^{4} / \mathrm{ml}$ solution. A volume of $5 \mathrm{ml}$ was inoculated to new culture bottles and cultured for $12 \mathrm{~h}$ before any treatment or assay. Ply of $0.5,1$, $2.5 \mu \mathrm{g} / \mathrm{ml}$ was added into the bottles and incubated for $24 \mathrm{~h}$ at $37^{\circ} \mathrm{C}$. PBS-treated dishes served as the control. Thereafter, changes in morphology were observed with light microscopy.

Transmission electron microscopy (TEM). The procedure for TEM analysis was performed as previously described (10). Briefly, HUVEC cells were exposed to $1 \mu \mathrm{g} / \mathrm{ml}$ of Ply for $12 \mathrm{~h}$. Thereafter, cells were rinsed twice with PBS, fixed overnight and post-fixed similarly with the procedure for scanning electron microscopy. The cells were placed and allowed to dehydrate through a graded ethanol series and subsequently infiltrated with liquid Araldite resin. Sections were doublestained with uranium acetate and lead citrate. Suitable areas were selected before TEM.

Detection of apoptosis with flow cytometry in vitro. To analyze the apoptosis with propidium iodide (PI) and Annexin V staining, HUVEC cells were exposed to either Ply $(0.5,1$, $2.5 \mu \mathrm{g} / \mathrm{ml}$ ) or PBS (control). After incubation for $12 \mathrm{~h}$, the cells were harvested according to the manufacturer's instructions, followed by staining with Annexin V-FITC and PI for flow cytoflometry.

Immunocytochemistry. HUVEC cells were incubated with $0.5 \mu \mathrm{g} / \mathrm{ml}$ Ply and PBS for $24 \mathrm{~h}$ at $37^{\circ} \mathrm{C}$, pelleted and washed with PBS, fixed (with $4 \%$ paraformaldehyde), and permeabilized for 15 min with $3 \% \mathrm{H}_{2} \mathrm{O}_{2}$. These cells were processed for immunocytochemistry with the corresponding antibodies. The $\mathrm{p} 38$ MAPK and the ERK1/2 antibodies were diluted $1: 50$ and 1:250, respectively, in $1 \%$ bovine serum albumin, and then cells were stained according to the manufacturer's instructions. Suitable areas were selected for observation of positevely-stained brown particles in the cytoplasm and/or the cell membrane under 10 high-power fields (magnification, $\mathrm{x} 400$ ). A computer image analysis system was used to calculate the mean density (MD) value of the positive cells, and to calculate the ratio, MD (pro)/MD (con), reflecting the level of protein expression.

Fluorometric analysis of caspase activities. HUVEC cells were treated either with Ply at a final concentration of $0.5 \mu \mathrm{g} / \mathrm{ml}$ or with PBS. The absorbance at the wavelength of $405 \mathrm{~nm}$ (A405) was measured according to the manufacturer is instructions. The activities of caspase- $3,-8$ and -9 were calculated as: Activity $=A_{\text {treated }} / A_{\text {control }}$.

Western blotting. HUVECs were incubated with $0.5 \mu \mathrm{g} / \mathrm{ml} \mathrm{Ply}$ or PBS for $12 \mathrm{~h}$. Cells were pelleted and washed with PBS for three times. These cells were lysed on ice in lysis buffer containing $10 \mathrm{mg} / \mathrm{ml}$ protease inhibitor (Roche, Mannheim, Germany) by gently shaking twice. The supernatant was obtained by $12,000 \mathrm{r} / \mathrm{min}$ of centrifugation at $4^{\circ} \mathrm{C}$ for $10 \mathrm{~min}$. The protein extracts were separated by sodium dodecyl sulfate-polyacrylamide gel electrophoresis and transferred to a polyvinylidene membrane. Blots were blocked and incubated with rat anti-human p38 MAPK or ERK1/2 primary antibodies(Cell Signaling Technology) or an anti- $\beta$-actin antibody (Santa Cruz Biotechnology, Inc.) overnight at $4^{\circ} \mathrm{C}$. Blots were rinsed, incubated with a horseradish peroxidaseconjugated secondary antibody, and developed using the ECL kit (Millipore, Billerica, MA, USA).

Statistical analyses. All data are presented as the mean \pm SD and were analyzed with the SPSS 17.0 software. A value of $\mathrm{P}<0.05$ was considered statistically significant.

\section{Results}

Penumolysin inhibits the proliferation of HUVECs. The viability of cells in the confluent monolayer of HUVECs was markedly suppressed by the different concentrations of Ply treatments for the indicated test periods when compared to the negative control with no pneumolysin treatment, as shown by the MTT data (Fig. 1A) $(\mathrm{P}<0.05)$. The growth of HUVEC cells was inhibited by pneumolysin in a dose- and time-dependent manner. The effect of pneumolysin $(0.5,1,2.5 \mu \mathrm{g} / \mathrm{ml})$ on the HUVEC morphology was observed under light microscopy (Fig. 1B). Significant morphological changes of HUVECs exposed to pneumolysin were observed. In the control dishes, monolayer cells were spindle-shaped, adherent, and showed typical 'cobblestone-like' morphological characteristics. When Ply was added, the micrographs show HUVECs had deviated from their typical appearance demonstrating that the number of viable cells was negatively-dependent on Ply concentrations. 


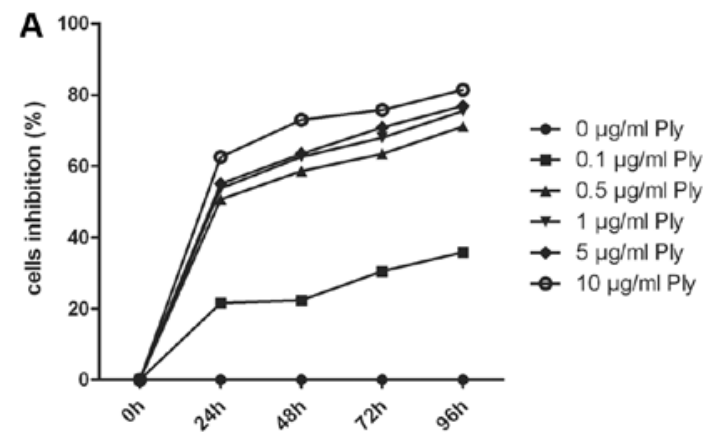

B

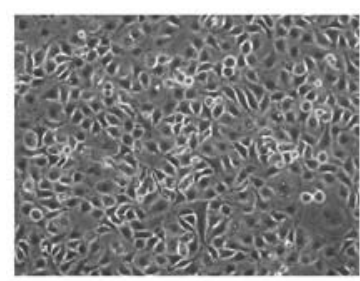

$0.5 \mu \mathrm{g} / \mathrm{ml}$ Ply

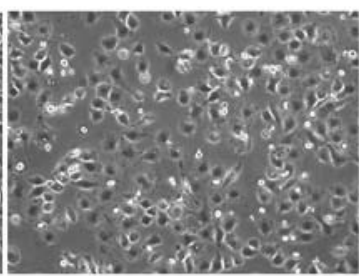

$1 \mu \mathrm{g} / \mathrm{ml}$ Ply

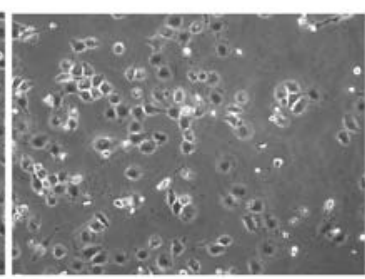

2. $5 \mu \mathrm{g} / \mathrm{ml}$ Ply

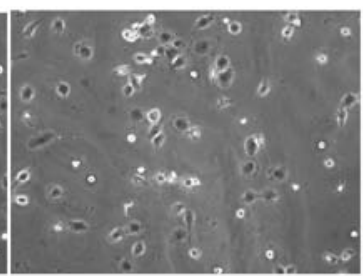

Figure 1. Effects of pneumolysin on HUVEC cell survival, proliferation and cell morphology (x100). (A) HUVECs were exposed to various concentrations of Ply $(0.1,0.5,1,5,10 \mu \mathrm{g} / \mathrm{ml})$ for $0,24,48,72$ and $96 \mathrm{~h}$. The growth of HUVECs was markedly suppressed in the Ply treated groups compared to the Ply mutant group or the control cells $(\mathrm{P}<0.05)$. The growth of HUVECs was inhibited by Ply in a dose- and time-dependent manner. (B) HUVECs were exposed to Ply for $12 \mathrm{~h}$ with indicated doses. In control dishes, cells showed the typical 'cobblestone-like' morphological characteristic. When exposed to pneumolysin, cells became winkled and the cell number decreased.
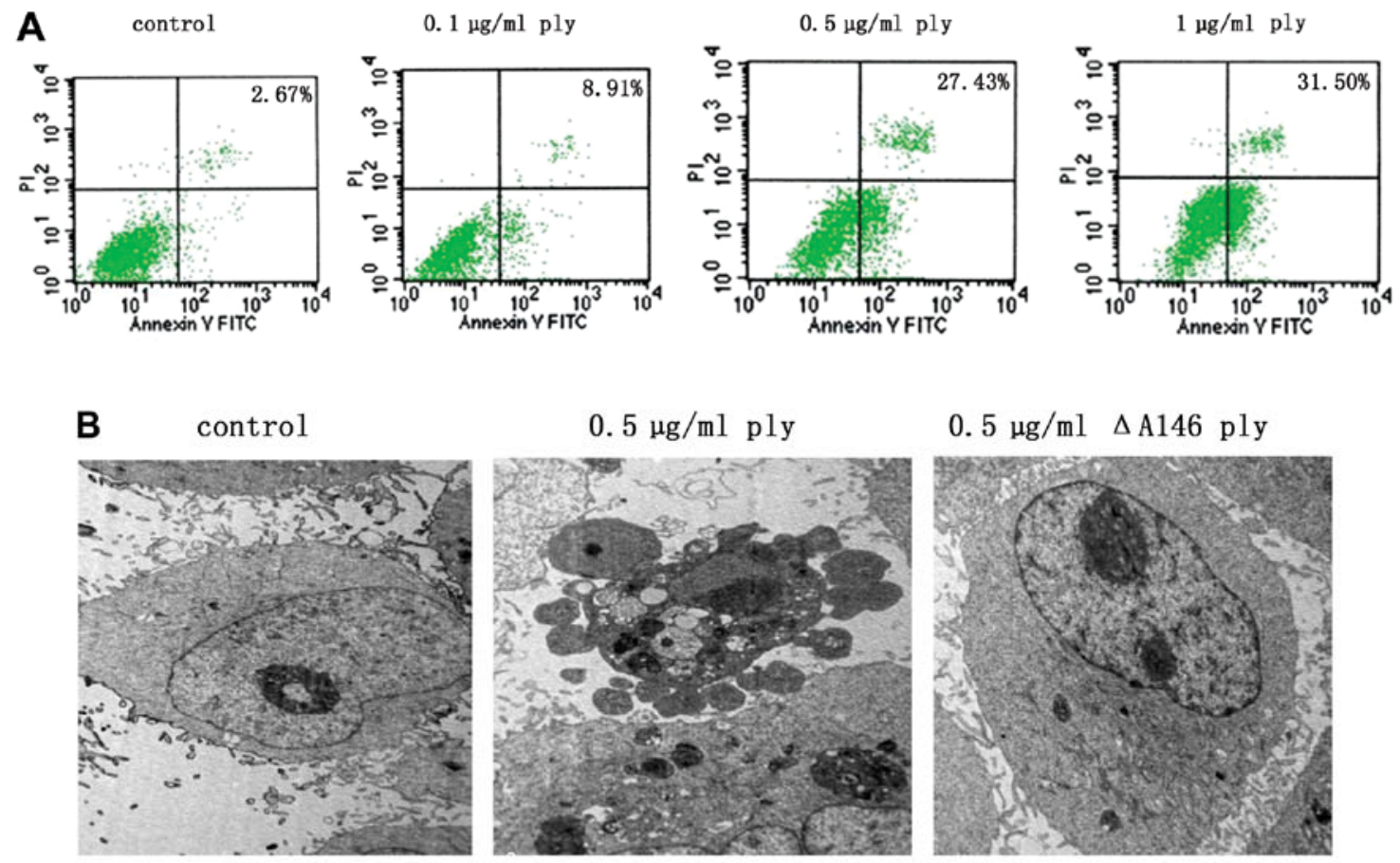

Figure 2. Apoptosis induced by pneumolysin. (A) Induction of apoptosis by pneumolysin as measured by flow cytometry. The HUVECs were treated with 0.1 , 0.5 and $1 \mu \mathrm{g} / \mathrm{ml}$ of pneumolysin or PBS for $12 \mathrm{~h}$. The apoptosis rates for $0.1 \mu \mathrm{g} / \mathrm{ml}$ pneumolysin treated group was $8.91 \%$, and when the concentration increased to 0.5 and $1 \mu \mathrm{g} / \mathrm{ml}$, the apoptosis rates were elevated to 27.43 and $31.50 \%$, respectively. A significant difference was observed compared to the control cells ( $\mathrm{P}<0.05$ ). (B) Apoptosis of HUVECs observed by transmission electron microscopy $(\mathrm{x} 8,000)$. HUVECs were exposed to $0.5 \mu \mathrm{g} / \mathrm{ml} \mathrm{pneumolysin}, 0.5 \mu \mathrm{g} / \mathrm{ml}$ $\triangle \mathrm{A} 146$ Ply or PBS for $12 \mathrm{~h}$.

Apoptosis of HUVECs exposed to pneumolysin. Considering Ply could inhibit the proliferation of HUVECs, we investigated its role in apoptosis induction of HUVECs. The HUVECs were treated with $0.1,0.5$ and $1 \mu \mathrm{g} / \mathrm{ml}$ of Ply or PBS for $12 \mathrm{~h}$
(Fig. 2A). The apoptosis rate was detected with flow cytometry after Annexin V/PI staining. The apoptosis rate for the $0.1 \mu \mathrm{g} / \mathrm{ml}$ Ply-treated group was $8.91 \%$, and the apoptosis rates were increased to 27.43 and $31.50 \%$ at the 0.5 and $1 \mu \mathrm{g} / \mathrm{ml}$ 


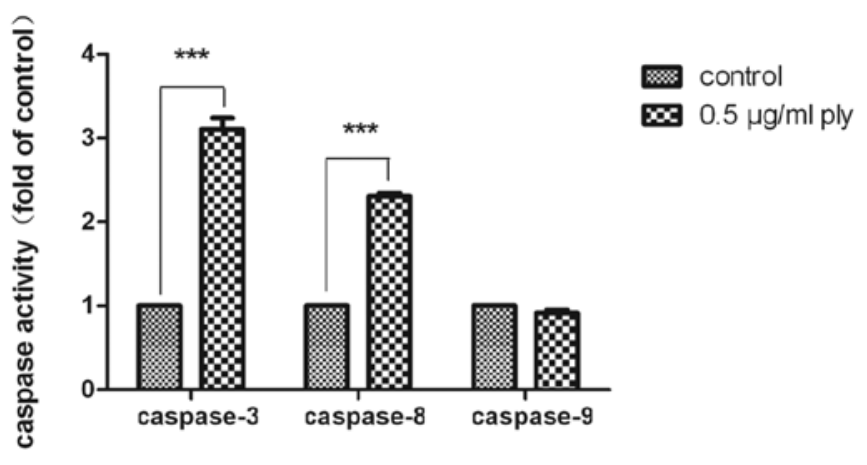

Figure 3. Activities of caspases-3, -8 and -9 . Following $12 \mathrm{~h}$ culture, HUVEC cells were treated either with Ply at a final concentration of $0.5 \mu \mathrm{g} / \mathrm{ml}$ or PBS as indicated. The activities of caspases-3, -8 and -9 were calculated as: Activity $=\mathrm{A}_{\text {treated }} / \mathrm{A}_{\text {control }}$. Values are compared between stimulated and nonstimulated cells. ${ }^{* * *} \mathrm{P}<0.0001$. Each bar represents the mean $\pm \mathrm{SD}$ of separate experiments.

Ply concentrations, respectively. A significant difference was observed compared to the control cells $(\mathrm{P}<0.05)$. TEM was carried out at the concentration of $0.5 \mu \mathrm{g} / \mathrm{ml}$ Ply. After $12 \mathrm{~h}$ exposure, typical apoptosis characteristics such as bubbles in the cytoplasm, chromatin condensation and apoptosis bodies were observed under TEM (Fig. 2B).

Pneumolysin induces the activities of caspases-8, -9, -3. Caspases play an important role in apoptosis. We therefore, investigated whether they are involved in the apoptosis of
HUVECs induced by Ply using caspase activity assays. Incubation of HUVECs with $0.5 \mu \mathrm{g} / \mathrm{ml}$ Ply led to the activation of caspases- 8 and -3 , but not caspase-9. Caspases were not activated in the controls (Fig. 3).

Activation of p38 MAPK and deactivation of ERK1/2. Next, we addressed whether the effects on HUVECs by Ply correlated with the activation and phosphorylation of p38 MAPK and ERK1/2. Using immunochemical assays, p38 MAPK and ERK1/2 were examined in HUVEC cells (Fig. 4A). Ply exposure led to a significant increase $(\mathrm{P}<0.05)$ in the phosphorylation of p38 MAPK compared with the control group. After Ply exposure, ERK1/2 in HUVECs was reduced compared to the control cells (Fig. 4B, C and D).

Pneumolysin-induced apoptosis of HUVECs could be blocked by 38 MAPK inhibitor. HUVEC cells were pretreated with $20 \mu \mathrm{M}$ SB-203580 (obtained from Cell Singaling Technology) (a p38 MAPK inhibitor) for $1 \mathrm{~h}$. The presence of the p38 MAPK inhibitor resulted in a significant decrease of the apoptosis rate in the Ply treatment group (Fig. 5) $(\mathrm{P}<0.05)$.

\section{Discussion}

Pneumolysin is an important exotoxin released by $S$. pneumoniae. Previous studies had reported that, exposure of neutrophils, macrophages, and epithelial cells to pneumolysin caused apoptosis and necrosis of the cells $(8,9,13)$. The present study demonstrated the apoptosis of HUVEC following
A

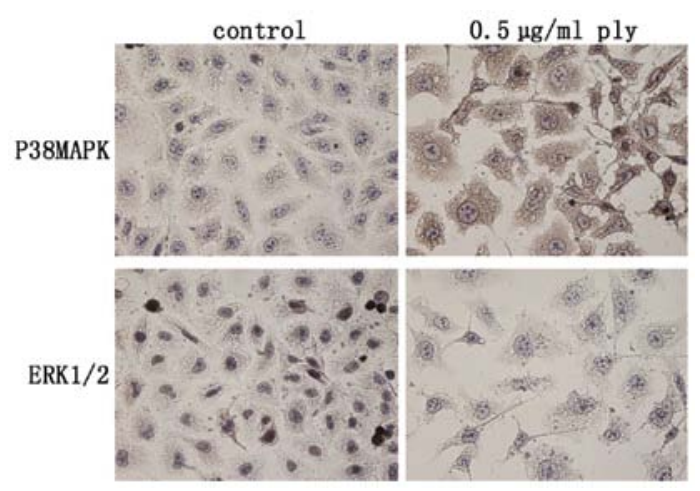

C

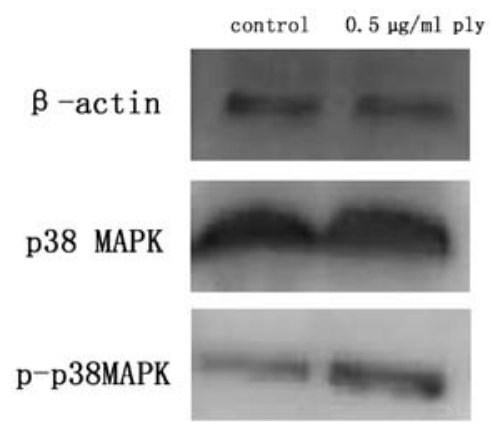

B

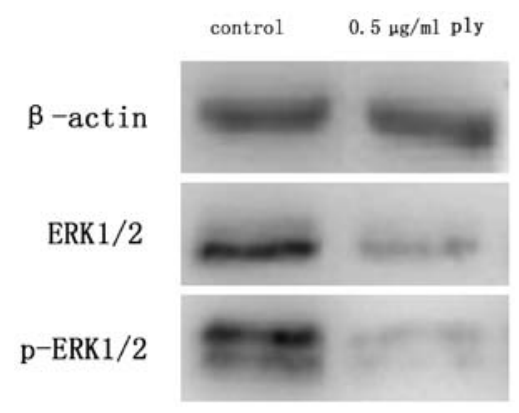

D

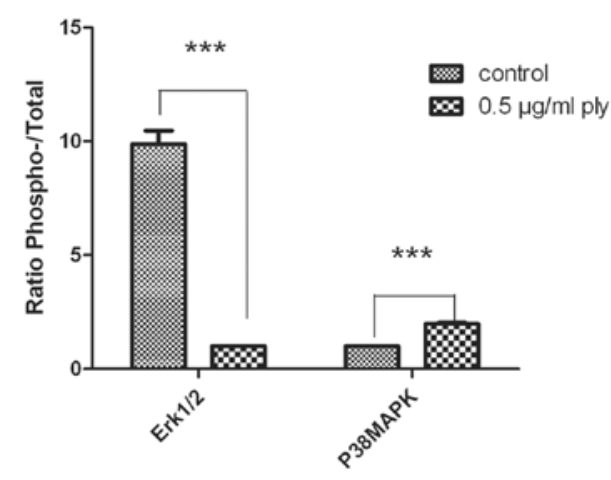

Figure 4. Ply induced the activation of $\mathrm{p} 38$ and reduced that of ERK 1/2. (A) HUVEC cells were incubated with $0.5 \mu \mathrm{g} / \mathrm{ml}$ Ply and PBS (control) for $24 \mathrm{~h}$ at $37^{\circ} \mathrm{C}$ (magnification, $\mathrm{x} 400$ ). Using immunocytochemical assays, p38 MAPK and ERK1/2 expression was examined in HUVEC cells. (C and D) Pneumolysin exposure led to a significant increase $(\mathrm{P}<0.05)$ in phospho-p38 MAPK compared to the control group. (B and D) After Ply exposure, phospho-ERK1/2 in HUVECs was reduced compared to the control cells. Values are compared between stimulated and nonstimulated cells. ${ }^{* * *} \mathrm{P}<0.0001$. Each bar represents the mean \pm SD of separate experiments. 

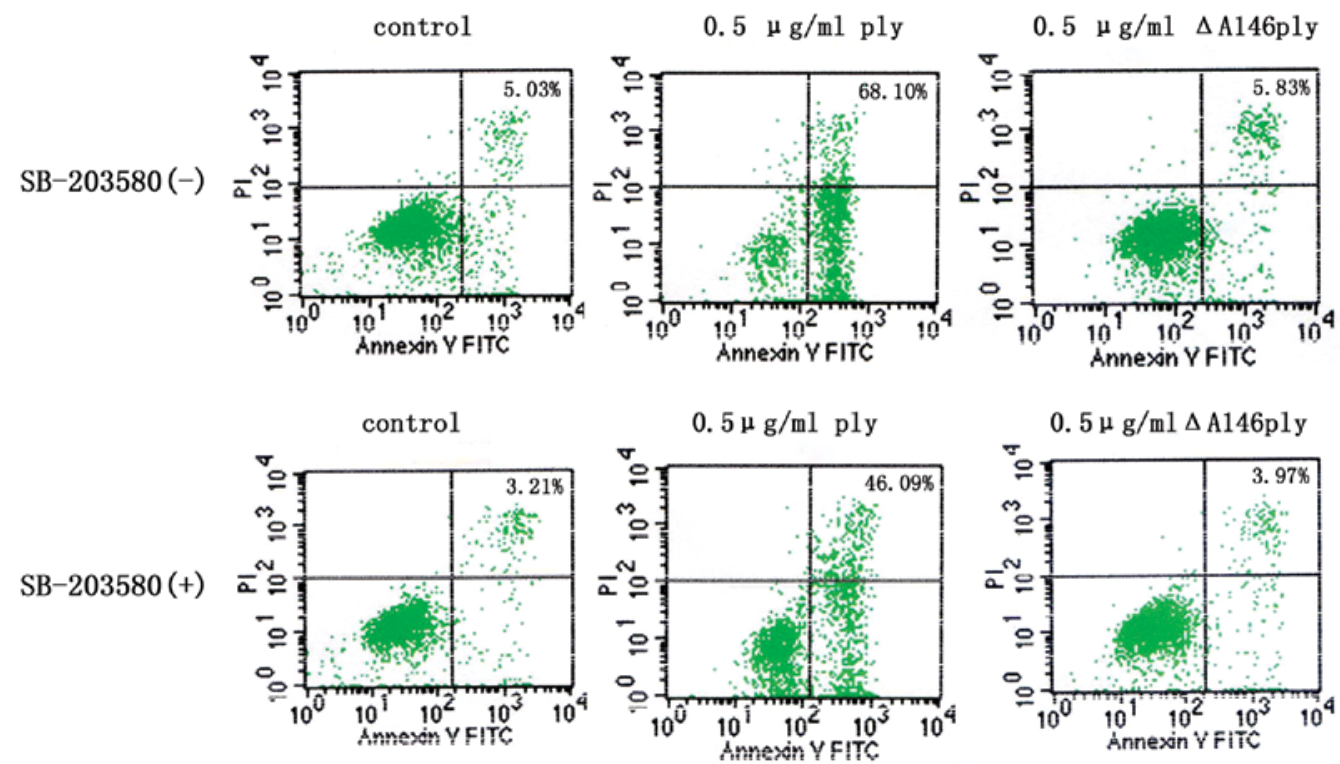

Figure 5. Effect of the p38 MAPK inhibitor SB-203850 on Ply-induced apoptosis. HUVECs were pretreated with $20 \mu$ M SB-203580 (a p38 MAPK inhibitor) for $1 \mathrm{~h}$ before treatment with $0.5 \mu \mathrm{g} / \mathrm{ml}$ of pneumolysin for $12 \mathrm{~h}$. Upper panel, no. SB-203580. The apoptosis rate was significant higher in Ply-exposed cells compared to control. Lower panel, pretreated with SB203580 followed by Ply exposure. The addition of SB-203580 significantly decreased the apoptosis rate induced by Ply $(\mathrm{P}<0.05)$.

pneumolysin exposure, and thus expanded the knowledge on pneumolysin induced apoptosis.

Basically, the endothelium forms a physical barrier that separates blood from tissue, and maintains as well as regulates barrier function against various kinds of stimuli such as inflammation (14). Moreover, they involve the earliest events in inflammation, such as the adhesion of immune cells (15). It is well known that ICAM-1, VCAM-1 and E-selectin are inducible by cytokines such as TNF- $\alpha$ during infections, and contribute to an increase in adhesion and chemokine release in endothelial cells (16). Thus, loss of endothelial barrier functions due to endothelial apoptosis, e.g. in the vasculature, could result in bacterial invasion and cause systemic bacterial infection.

In the present study, the effect of pneumolysin on HUVECs was clearly demonstrated by light microscopy and TEM observations. From the images, one can clearly see that HUVECs underwent morphological changes, from the typical spindle-shaped, to ones that had wrinkled and round shape; the cell number decreased (Fig. 1B). Besides, apoptosis was observed under TEM, and further confirmed by Annexin V/PI staining. Hahne et al (17) reported that pneumolysin interaction with brain microvascular endothelial cells led to increased detachment of cells in accordance with our results. Therefore, pneumolysin-mediated apoptosis of endothelial cells, as shown in this study may pave the way for further invasion and eventually systemic infection.

Cell apoptosis is a critical process controlling the host balance under normal or stress conditions. The modulation of apoptosis was related to a series of complex caspase reactions. There are two typical caspase-associated pathways leading to apoptosis: one involves the activation of caspase- 8 , while the other is caspase- 9 dependent and involves the mitochondria. Both pathways will eventually activate caspase- 3 , initiate the entire caspase cascades, and hence induce apoptosis. It is controversial whether pneumolysin-induced apoptosis is dependent on caspases. Therefore, we determined the activity of caspases $-3,-8$ and -9 , which constitute the two typical apoptosis-associated pathways. HUVECs demonstrated increased activity of caspases-3 and -8 , whereas caspase-9, implicating mitochondrial involvement, was not activated in this study. This suggests that pneumolysin-induced apoptosis in HUVECs occurs through caspase-8 (extrinsic pathway) but not caspase-9 (intrinsic pathway).

MAPK kinase signaling pathways were activated in response to the inflammation response. p38 and ERK1/2 are two major downstream MAPK cascades $(18,19)$. Therefore, we hypothesized that p38 and ERK1/2 may contribute to Ply-induced endothelial cell apoptosis. In the present study, pneumolysin promoted not only the activity but also the phosphorylation of p38 MAPK. In contrast, not only the activity but also the phosphorylation of ERK $1 / 2$ was inactivated in HUVECs. It is not clear whether a crosstalk between the two signaling pathways led to the apoptosis induced by pneumolysin. However, we demonstrated that activated $\mathrm{p} 38$ is required for pneumolysin-induced apoptosis, as shown by the ability of the p38 inhibitor to prevent cells from undergoing apoptosis.

In conclusion, this study provides evidence in support of the involvement of p38 MAPK in Ply-induced HUVEC apoptosis and the apoptosis is dependent on the activation of caspases- 3 and -8 .

\section{Acknowledgements}

This study was supported by a grant from the National Natural Scince Foundation of China (no. 30872363) and the Chongqing Municipal Education Commission of Science and Technology Research Project (no. KJ100310). The funders had no role in study design, data collection and analysis, decision to publish, or preparation of the manuscript. 


\section{References}

1. Bogaert D, De Groot R and Hermans PW: Streptococcus pneumoniae colonization: the key to pneumococcal disease. Lancet Infect Dis 4: 144-154, 2004.

2. Mitchell TJ and Andrew PW: Biological properties of pneumolysin. Microb Drug Resist 3: 19-26, 1997.

3. Paton JC, Berry AM, Lock RA, et al: Cloning and expression in Escherichia coli of the Streptococcus pneumoniae gene encoding pneumolysin. Infect Immun 54: 50-55, 1986.

4. Kanclerski K and Möllby R: Production and purification of Streptococcus pneumoniae hemolysin (pneumolysin). J Clin Microbiol 25: 222-225, 1987.

5. Kyriakis JM and Avruch J: Mammalian mitogen-activated protein kinase signal transduction pathways activated by stress and inflammation. Physiol Rev 81: 807-869, 2001.

6. Shi Y: Machanisms of caspase activation and inhibition during apoptosis. Mol Cell 9: 459-470, 2002.

7. Alnemri ES, Livingston DJ, Nicholson DW, Salvesen G, Thornberry NA, Wong WW and Yuan J: Human ICE/CED-3 protease nomenclature. Cell 87: 171, 1996.

8. N'Guessan PD, Schmeck B, Ayim A, et al: Streptococcus pneumoniae R6x induced p38 MAPK and JNK-mediated caspase-dependent apoptosis in human endothelial cells. Thromb Haemost 94: 295-303, 2005.

9. Colino J and Snapper CM: Two distinct mechanisms for induction of dendritic cell apoptosis in response to intact Streptococcus pneumoniae. J Immunol 171: 2354-2365, 2003.

10. Braun JS, Hoffmann O, Schickhaus M, et al: Pneumolysin causes neuronal cell death through mitochondrial damage. Infect Immun 75: 4245-4254, 2007.

11. Beurg M, Hafidi A, Skinner L, et al: The mechanism of pneumolysin-induced cochlear hair. J Physiol 568: 211-227, 2005.
12. Schmeck B, Gross R, N'Guessan PD, Hocke AC,Hammerschmidt S, Mitchell TJ, Rosseau S, Suttorp N and Hippenstiel S: Streptococcus pneumoniae induced caspase 6 dependent apoptosis in lung epithelium. Infect Immun 72: 4940-4947, 2004.

13. Kirkham LA, Kerr AR, Douce GR, Paterson GK, Dilts DA, Liu DF and Mitchell TJ: Construction and immunological characterization of a novel nontoxic protective pneumolysin mutant for use in future pneumococcal vaccines. Infect Immun 74: 586-593, 2006.

14. Engelich G, White M and Hartshorn KL: Neutrophil survival is markedly reduced by incubation with influenza virus and Streptococcus pneumoniae: role of respiratory burst. J Leukoc Biol 69: 50-56, 2001.

15. Csortos C, Kolosova I and Verin AD: Regulation of vascular endothelial cell barrier function and cytoskeleton structure by protein phosphatases of the PPP family. Am J Physiol Lung Cell Mol Physiol 293: L843-L854, 2007.

16. Osborn L: Leukocyte adhesion to endothelium in inflammation. Cell 62: 3-6, 1990.

17. Hahne M, Jager U, Isenmann S, Hallmann R and Vestweber D: Five tumor necrosis factor-inducible cell adhesion mechanisms on the surface of mouse endothelioma cells mediate the binding of leukocytes. J Cell Biol 121: 655-664, 1993.

18. Zysk G, Schneider-Wald BK, Hwang JH et al: Pneumolysin is the main inducer of cytotoxicity to brain microvascular endothelial cells caused by Streptococcus pneumoniae. Infect Immun 69: 845-852, 2001.

19. Niyonsaba F, Ushio H, Nagaoka I, Okumura $K$ and Ogawa $H$ : The human beta-defesins $(-1,-2,-3,-4)$ and cathlicidin LL-37 induce IL-18 secretion through $\mathrm{p} 38$ and ERK MAPK activation in primary human keratinocytes. J Immunol 175: 1776-1784, 2005. 